\section{TV-Werbung lässt Alte meist jung aussehen}

\author{
Forscher des Instituts für Soziologie und Genderforschung der Deutschen \\ Sporthochschule Köln haben untersucht, welches Bild von älteren Menschen \\ die Fernsehreklame inszeniert. Alte kommen darin eher selten vor, und wo \\ doch, sehen sie meist nicht alt aus.
}

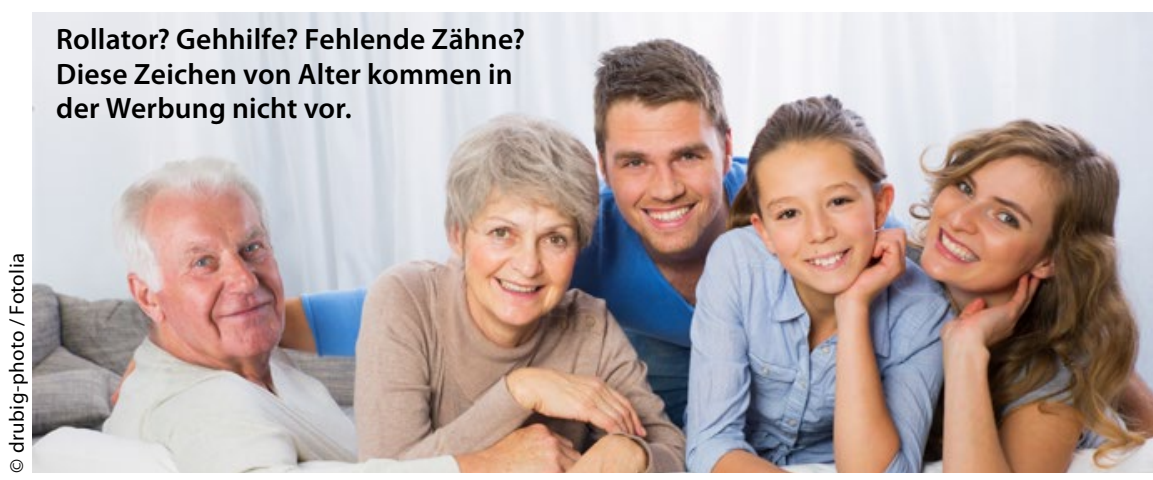

$T_{\text {fitim }}^{\text {he }}$ heresa Hoppe und Kolleginnen haben für ihre Studie TV-Werbespots analysiert, um Erkenntnisse über die Repräsentation der Generation 50plus in der Produktreklame zu gewinnen. Der Anteil der Werbespots mit älteren Prota-gonisten lag im Durchschnitt bei 10,5\%. Dabei gab es Unterschiede zwischen öffentlichrechtlichen und privaten Sendern. Spots in Ersteren hatten zu 25\%, solche in Letzteren zu 9\% einen Altersbezug. Zum Vergleich: Der Anteil der 50-Jährigen und Älteren an der Bevölkerung der Bundesrepublik beträgt rund $44 \%$.

114 Reklamefilme analysierten die Forscherinnen genauer. Rund drei Viertel der abgebildeten Älteren waren den jungen Alten zuzuordnen und hauptsächlich aufgrund latenter Falten überhaupt als alt zu identifizieren. Dargestellt wurden meist Männer (72\%), ältere Frauen waren deutlich unterrepräsentiert. Ginge es nach dem Bild in der Werbung, haben Alte nur in 1,5\% der Spots einen eingefallenen Mund. Prothesen sind noch rarer $(0,8 \%)$, ebenso wie Gehhilfen oder Rollatoren (0,8\%). Rollstühle kamen gar nicht vor.

In rund $21 \%$ der Werbespots mit $\mathrm{Al}-$ tersbezug wurde für Lebensmittel geworben. Versicherungen waren wie Kosmetika mit je $9 \%$ vertreten. Dabei handelte es sich hauptsächlich um regenerative, praktisch nie um verschönernde und selten um Produkte zur Körperpfle- ge. Geworben wurde zudem für medizinische Hilfsmittel, Reisen und Medikamente. In rund 5\% der Spots ging es um Technik, wie beispielsweise Mobiltelefone oder Staubsauger. Waren ältere Menschen in Werbespots zu sehen, galt die Botschaft mehrheitlich nicht altenspezifischen, sondern altersübergreifenden also nicht hauptsächlich dazu verwendet, eine Kommunikation speziell „für Ältere“ zu generieren. Vielmehr sei anzunehmen, dass die Spots mit dieser Strategie auch Ältere ansprechen, also inkludierend wirken und über ältere Protagonisten bestimmte Inhalte symbolisiert und vermittelt werden sollten, so die Kölner Wissenschaftlerinnen. In Werbefilmen, die für ein altersunspezifisches Produkt warben, wurde das Alter überwiegend positiv dargestellt. Wo es sich um altersspezifische Produkte handelte, war es hingegen negativ visualisiert.

Die Darstellung Älterer in der Werbung werde aufgrund der Verbindung mit häufig negativen Eigenschaften vermieden, um die mehrheitlich positive Werbewelt nicht negativ zu beeinflussen, resümieren Hoppe und Mitarbeiterinnen mit Blick auf den verglichen mit dem Bevölkerungsanteil geringen Repräsentationsgrad. Und alte Alte fänden noch weniger Beachtung als junge Alte. „Die Inszenierung von Alter in der Werbung konzentriert sich auf das, junge Alter, Produkten. Das Merkmal „Alter“ wurde während Hochaltrigkeit kaum in Erscheinung tritt", schreiben die Forscherinnen.

(rb)

Hoppe T et al. Inszenierung von Alter(n) und älteren Menschen in TV-Werbespots. Z Gerontol Geriat 2015, online 7. Juli; doi: 10.1007/s00391015-0923-y

\section{Kommentar}

Mal wieder eine Kampagne für die Pflegeberufe. Mich strahlen fröhliche Alte an, gut angezogen und mopsfidel. Umgeben von Familienmitgliedern werben Sie auf großen Plakaten dafür, dass (junge) Menschen den Pflegeberuf erlernen. Die Broschüre vom Bundesministerium für Gesundheit - Pflegestärkungsgesetz - auch hier der attraktive alte Mensch. Ich frage mich, wieso bei diesen Bildern junge Menschen auf die Idee kommen sollten, den Pflegeberuf zu ergreifen? Die Alten scheinen doch ganz gut zurechtzukommen. Selbst mein geliebter $\mathrm{Be}$ rufsverband zeigt attraktive Pflegebedürftige bei bildergestützten Kampagnen.

T. Hoppe und ihre Kolleginnen haben untersucht, welches Bild alte Menschen in unserer Werbung vermitteln. Zwar sind $44 \%$ der Menschen in Deutschland älter als 50 Jahre. In Werbespots kommen diese aber kaum vor. Und wenn wir Alte darin sehen, sind sie zu $72 \%$ männlich, grauhaarig, „jungaltrig“. Sie werben für Ernährung, regenerierende Kosmetikartikel und Versicherungen. Das Alter wird transportiert über Falten, Augenschatten und Tränensäcke, schlaffe Halspartie und Brille. Rollator? Gehhilfe? Hörgerät? Fehlende Zähne? - Fehlanzeige. Diese Zeichen von Alter kommen in der Werbung nicht vor. Welches Bild der Alten transportiert unsere Gesellschaft? Haben wir Angst vor der Realität? Im Zuge der demografischen Entwicklung, steigender Altersarmut, und Veränderungen in den Versorgungsstrukturen müssen wir uns wohl generell auf ein ehrlicheres Bild von Alter in der Öffentlichkeit einlassen. Wir werden es als Gesellschaft sonst versäumen, unseren Alten (und am Ende uns selbst) ein anständiges Leben zu sichern - egal, ob pflegebedürftig oder nicht.

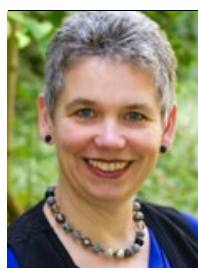

Christine Vogler Wannsee Schule e.V. Leitung Pflegeschulen Zum Heckeshorn 36 14109 Berlin cvogler@wannseeschule.de 